\title{
Os Modelões e a Mera Formalidade: Produção de Decisões e Sentenças em uma Vara Criminal da Baixada Fluminense do Rio de Janeiro ${ }^{1}$
}

\author{
Modelões and Mere Formality: Production of Decisions and \\ Sentences in a Criminal Court of the Baixada Fluminense of \\ Rio De Janeiro
}

\author{
Marilha Gabriela Reverendo Garau \\ Universidade Federal Fluminense, Niterói, Rio de Janeiro, Brasil
}

\section{RESUMO}

Neste artigo, descrevo de que forma são produzidas decisões e sentenças numa Vara Criminal da Baixada Fluminense do Rio de Janeiro. A interlocução que me permitiu observar as práticas e discursos dos atores que atuam no gabinete como parte do processo de tomada de decisões aconteceu entre março e outubro de 2018, durante visitas periódicas semanais à Comarca. A descrição densa dessas práticas, a partir da análise das rotinas internas do gabinete, aponta para a prevalência de modelos de decisões e sentenças que já foram tomadas antes dos fatos serem levados ao conhecimento da juíza titular da vara. Tal característica revela a prevalência de uma prática que classifico como procedimentalização que, por sua vez, está orientada pela preservação da presunção de culpa do réu ao longo do processo. Ao que parece, as etapas que se pretendem defensivas não representam uma oportunidade de defesa do réu senão um fim em si mesmas, portanto, são levadas a cabo por mera formalidade. Percebo nessa dinâmica uma rotina que separa os casos semelhantes dos casos excepcionais. O ritual das audiências também foi percebido como parte dessa procedimentalização que será inevitável nos casos semelhantes, mas que

1 O trabalho foi realizado com apoio da Coordenação de Aperfeiçoamento de Pessoal de Nível Superior (CAPES). Tese defendida no Programa de Pós-graduação em Sociologia e Direito da Universidade Federal Fluminense (PPGSD/UFF). 
pode representar uma oportunidade de apresentar ao julgador um caso excepcional.

Palavras-chave: Justiça criminal, Sentenças, Práticas judiciárias, Presunção de inocência.

\section{ABSTRACT}

In the present work I describe how decisions and sentences are produced in a Criminal Court of the Baixada Fluminense in Rio de Janeiro. The dialogue that allowed me to observe the practices and speeches of the actors who work in the judge office as part of the decision-making process took place between March and October 2018, during periodic weekly visits to the Comarca. The dense description of these practices, based on the analysis of the judge office's internal routines, points to the prevalence of models of decisions and sentences that were already taken before the facts were brought to the attention of the judge holding the court. This characteristic reveals the prevalence of a practice that I classify as procedimentalização, which, in turn, is guided by the preservation of the defendant's presumption of guilt throughout the process. Apparently, the defensive steps are not an opportunity to defend the defendant but an end in themselves, therefore, they are carried out by mere formality. In this dynamic, I perceive a routine that separates similar cases from exceptional cases. The hearings ritual was also perceived as part of this procedimentalização that will be inevitable in similar cases, but that can represent an opportunity to present the judge with an exceptional case.

Keywords: Criminal justice, Sentences, Judicial practices, Presumption of innocence.

\section{A ROTINA DO GABINETE: "AQUI ONDE AS DECISÕES SÃO TOMADAS"}

O gabinete do juízo da Vara Criminal da Baixada Fluminense divide-se fisicamente em dois espaços distintos e complementares: a sala dos servidores e a sala da juíza. A porta de madeira à esquerda do corredor é identificada por uma pequena placa vermelha "GABINETE". O gabinete é um lugar cujo simbolismo explica bastante sobre a relação de hierarquia do juízo, já que é compreendido pelos servidores da vara como o espaço de mais alta hierarquia. O local não é passível do acesso de qualquer pessoa que trabalhe à disposição do juízo. Apenas aqueles profissionais específicos que trabalham no gabinete estão autorizados a circular por esse espaço.

É que o acesso ao gabinete prescinde contato direto com a juíza titular da vara. Tive pouca abertura no espaço do cartório, mas pelo simples fato de estar no "gabinete" percebi que 
era tratada pelos profissionais que ali trabalhavam de forma diferenciada, o que me explicou sobre as hierarquias simbólicas entre os espaços. Em uma certa ocasião, fui ao cartório em nome da secretária da juíza pedir que um documento do processo fosse retificado. O processo foi enviado para o gabinete sem que tivessem formalizado documentalmente que os autos "estavam em conclusão". A serventuária que me atendeu dirigiu-se à profissional responsável pelo equívoco pedindo imediata correção do erro "para tudo que você estiver fazendo, é para o gabinete", ordenou. A expressão "para o gabinete" de fato surtia um efeito imediato nas pessoas. As demandas do gabinete eram sempre mais relevantes do que quaisquer outras, o que revela a hierarquia entre os espaços, embora ambos sejam parte de uma mesma organização: o juízo.

No gabinete, trabalham Sandra e Márcio. Sandra foi apresentada a mim pela juíza como a sua secretária e o "seu braço direito". Ela se tornou uma interlocutora fundamental dentro do gabinete, pois tinha um papel crucial naquele espaço, já que era a responsável por organizar todo o trâmite interno e promover a interação entre o gabinete e o cartório. Nessa Vara Criminal, os processos ainda eram físicos porque a implementação do sistema de processos virtuais não se consolidou em todas as comarcas do estado, principalmente nas da baixada e interior. Sandra era a responsável pelo ir e vir dos processos físicos do gabinete para o cartório e vice-versa.

O cartório se diferencia do gabinete porque está destinado ao processamento das demandas. Dessa forma, o cartório pratica atos que não possuem caráter decisório dentro do processo, basicamente promovendo a interação entre as decisões do gabinete e os demais atores do processo (réus, vítimas, defesa e acusação). Por exemplo, quando um advogado apresenta um pedido sobre liberdade provisória do réu, a petição não é entregue diretamente para o gabinete, mas para o cartório, que verificará se o processo pode ser fisicamente remetido ao gabinete para que a decisão sobre a liberdade provisória do réu seja tomada. Do mesmo modo, se o gabinete determina que alguma das partes tem o prazo de 15 dias para se manifestar sobre algum ato do processo, é o cartório que informará à parte (próprio réu, advogados, defensores ou promotores) acerca da decisão do gabinete. Ao contrário dos documentos produzidos no cartório, aqueles confeccionados pelo gabinete têm centralidade dentro no processo criminal, já que produzem efeito no mundo dos fatos, decidindo sobre a liberdade, prisão, culpa e inocência dos réus.

Além de possibilitar essa dinâmica processual, Sandra era a principal responsável pela organização do gabinete como um todo, por isso ela interagia frequentemente com a juíza, mantendo uma relação de proximidade. O gerenciamento da agenda da magistrada era de total responsabilidade da secretária, incluindo assuntos que nem sempre se referiam às atividades profissionais da juíza, tais como o agendamento de consultas médicas, administração de ques- 
tões bancárias e até agendamento de revisão do carro.

Sandra tinha 49 anos. Morava com o marido e o filho adolescente na Tijuca, Zona Norte do Rio de Janeiro. Era funcionária do tribunal de justiça há mais de 15 anos, nove deles atuando como secretária da juíza, por quem nutria estima e admiração. Dentre as suas funções, ela também tinha o dever de manter os processos organizados, impulsionando o fluxo interno de produção das decisões, distribuindo os autos físicos entre as outras três pessoas que, assim como ela, trabalhavam na sala dos servidores. Sandra tinha uma rotina de receber os processos vindos em conclusão do cartório e dividi-los nas mesas e prateleiras identificadas com os nomes SANDRA, MÁRCIO, ESTAGIÁRIO (1) e ESTAGIÁRIO (2). Cada um desses atores tinha seus próprios lugares, demarcados por mesas e divisórias de MDF sobre as quais repousavam os respectivos computadores e materiais de trabalho, dentre objetos de escritório propriamente dito como grampeadores, clips e afins. Havia também alguns manuais de direito constitucional e penal separados no canto das divisórias.

Todos trabalhavam com uma meta de produtividade semanal que começava na segunda-feira e terminava na quinta-feira, dia reservado pela juíza para assinar todos os documentos produzidos pelos profissionais durante a semana. Apesar da especificidade, todos os dias, no final da tarde, Sandra levava os processos com as decisões e sentenças confeccionadas ao longo do dia para o gabinete da juíza, empilhando-os numa prateleira localizada à lateral da enorme mesa da magistrada.

A sala da juíza era menor do que o local destinado ao trabalho dos servidores, no entanto, mais aconchegante. Havia um sofá preto de dois lugares ao lado da porta para o qual davam de costas duas cadeiras acolchoadas, dispostas na barra da grande mesa de madeira na qual sempre havia uns poucos processos empilhados no extremo oposto do computador de mesa e um vade mecum do ano corrente se destacava lado a lado de um porta retrato com uma foto da juíza, seu marido e filhos, tendo como cenário de fundo a capital da toscana na Itália, no alto da Ponte Vecchio, da bela Florença.

A outra porta do gabinete, situada no lado direito da sala, se abria para uma estrutura invisível de corredores. Era a porta por onde a juíza chegava ao trabalho todos os dias, uma vez que não passava pela sala dos servidores para acessar o seu gabinete. A cadeira de escritório da juíza dava de costas para a uma janela que nunca soube para onde dava a vista, sempre me perguntava se aquela janela se abria para uma paisagem urbana ou para o interior do próprio prédio do tribunal, mas nunca pude descobrir, já que na integralidade de meus dias naquele lugar, foi escondida pelas persianas fechadas.

Além de Sandra, a juíza também tinha um assessor. Márcio era bastante jovem, ainda 
não havia completado 30 anos. Ele foi convocado pelo concurso que o aprovou para a carreira de analista judiciário há pouco mais de três anos. A aprovação foi anterior à sua formatura, quando ainda cursava bacharelado em Direito na Universidade Federal do Rio de Janeiro (UFRJ), mas ele só foi empossado dois anos após a conclusão do curso, no tempo em que estudava na Escola da Magistratura do Estado do Rio de Janeiro (EMERJ). Ele tinha relações de proximidade com a juíza. Era filho de um parente. Por isso, alguns meses após a sua convocação, a juíza redigiu um ofício ao setor de pessoal do tribunal de justiça do Rio de Janeiro solicitando que ele fosse removido para aquela vara. Márcio não passou pelo cartório, foi direto para o gabinete trabalhar como assessor da juíza, recebendo uma rubrica adicional pelo cargo. Ele era um rapaz bastante reservado e introspectivo. Estava sempre muito concentrado em suas atividades. O trabalho de Márcio era confeccionar as sentenças. Essa tarefa também era parte do trabalho de Sandra.

Para além da relação de poder inerente à hierarquia da juíza com relação aos seus assessores, percebo entre eles aquilo denominado por Goffman (2011) como ritual da interação. A relação de cumplicidade entre estes atores é regida pela discrição que evitava o conflito e mantinha a regularidade da produção de decisões e sentenças. A juíza raramente revisava o conteúdo dos documentos produzidos por esses atores, ao contrário, cada um deles tinha funções específicas e bem delimitadas, sob as quais nunca debatiam. A rotina era bem definida e nunca questionada.

Havia uma dinâmica previamente estabelecida entre eles e a juíza para determinar a distribuição dos casos e a confecção de sentenças. Via de regra cada um deles acompanhava um dia de audiência na semana, na condição de assistente, sendo responsáveis pela relatoria dos casos e confecção dos documentos para assinatura das partes no momento da Audiência de Instrução e Julgamento. Assim, ficava a cargo daquele que assessorou no dia da audiência, a confecção do denominado "projeto de sentença" que nada mais era do que a sentença propriamente dita, ratificada pela juíza pela assinatura automática e raramente antecedida da leitura dos papéis. Sempre na quinta-feira, com o intuito de esvaziar, o mais depressa possível, a pilha da semana.

\section{$\star * *$}

O presente artigo é parte da minha pesquisa de tese de doutorado, uma etnografia escrita a partir do referencial de comparação por contraste de processos e julgamentos de casos envolvendo tráfico de drogas no Brasil e na Espanha para compreender como os atores responsáveis pela condução dos processos de apuração e julgamento desse tipo penal acionam suas 
percepções e moralidades no fazer justiça (GARAU, 2020). Especificamente neste trabalho pretendo descrever os discursos e práticas dos atores responsáveis pela elaboração de decisões e sentenças na Vara Criminal da Baixada Fluminense do Rio de Janeiro onde realizei parte da pesquisa de doutorado. De março a outubro de 2018 estive em contato direto com todos os atores que participam do processo decisório no espaço do gabinete e da sala de audiências. A partir daí, passei a conhecer toda a rotina de trabalho daqueles atores e da própria juíza titular, desde o recebimento dos processos passando pelas tomadas de decisões, audiências e sentenciamento dos casos.

A análise é construída tendo como perspectiva orientativa os referenciais da antropologia jurídica que, por sua vez, olha para o direito como uma parte constitutiva da sociedade. Geertz (1998) frisa que o direito não é uma simples extensão de uma sociedade moralmente constituída, mas parte de um conjunto de realidades culturais que têm papel ativo em determinada sociedade. Assim, este artigo lança mão de um empreendimento de natureza etnográfica, situado no campo da Antropologia do Direito, que estuda as funções, a organização, as estruturas, os princípios e os valores que orientam a atuação das instituições inseridas no campo jurídico. Assim, o trabalho valoriza a apresentação do ser em detrimento do dever ser.

Além da própria juíza, minha principal interlocutora no campo, sua secretária também se tornou uma frequente interlocutora da pesquisa, sobretudo porque ela era a responsável pela organização dos fluxos do gabinete, bem como pela redação da maior parte das decisões e sentenças. No dia a dia, ela sempre me contava sobre casos que acreditava que me interessariam, as rotinas da juíza, os seus entendimentos na aplicação da lei, personalidade e vida pessoal. Depois de algum tempo no campo, a secretária começou a me tratar como uma espécie de estagiária. Redigi, em mais de uma ocasião, decisões sobre liberdade provisória e absolvições sumárias. Raramente tive contato com o cartório, apenas eventualmente quando a secretária me pedia para buscar algum processo ou levar um documento ou ofício para que o responsável pelo expediente assinasse. Logo no primeiro mês frequentando a Vara Criminal, comecei a ter contato com os defensores e promotores que eram vinculados à Comarca. Ao todo, três promotores e quatro defensores revezavam a condução das duas Varas Criminais da cidade. A proximidade com a juíza possibilitou que eu também interagisse com eles. 


\section{PROCEDIMENTALIZAÇÃO (DA CULPABILIDADE) PELAS DECISOES}

No caso do gabinete da Vara da Baixada Fluminense, a maior parte dos denominados projetos de sentença já estão prontos e precisam apenas ser preenchidos considerando os fatos do caso a ser julgado. Sandra e Márcio têm em seus respectivos computadores e pendrives inúmeros modelos de decisões e sentenças padronizadas. As pastas são categorizadas pelo tipo de documento a ser confeccionado, considerando o efeito jurídico por eles produzidos, nos termos a seguir: a) decisões interlocutórias são os atos que, embora tenham natureza decisória, não põe fim ao processo (por exemplo, decisões sobre absolvições sumárias, pedidos de liberdade provisória, deferimento de produção de provas etc.); b) despachos são atos que impulsionam o processo e demandam a atuação do cartório para que outros atores possam se manifestar (por exemplo, abrir prazo para apresentação de alegações finais do Ministério Público, intimação de testemunhas etc.); c) sentenças diferem dos demais atos por resolver sobre o mérito do processo, ou seja, decidir sobre a culpa e inocência dos réus, bem como sobre o quantum de pena a ser aplicado no caso concreto.

Os despachos e decisões interlocutórias são preenchidos pelas estagiárias que trabalham no gabinete. Marina e Fernanda dividem uma prateleira etiquetada com as suas funções. A separação e seleção dos casos que devem ir para cada uma delas está sob a incumbência de Sandra, mas é feito de forma aleatória. A maior parte desses processos trata de pedidos de absolvição sumária e liberdade provisória. O trabalho das estudantes de Direito é bastante mecânico e consiste em verificar qual modelo de decisão se adequa melhor ao pedido apresentado pela parte.

Depois de escolhido, o modelo é preenchido com os dados do réu e do processo. As estagiárias devem imprimir uma via da decisão e colocá-la solta na primeira parte do processo, entre a contra capa e a primeira folha. No fim do dia, as pilhas de processos com as decisões redigidas pelas estagiárias são levadas para o gabinete da juíza. Cada uma é identificada com o nome daquela que preencheu o documento, bem como com a data de confecção. As decisões não são assinadas no dia em que são confeccionadas, por isso as datas são registradas, visando evitar um acúmulo exagerado de expedientes decisórios sem assinatura. No dia reservado para essa atividade, a juíza seleciona as pilhas para assinar, sempre da mais antiga para a mais nova.

É interessante notar que as duas jovens têm pouco contato com a juíza. Por conta disso, as estagiárias têm como referência para o preenchimento das decisões Sandra e Márcio, que as orientam em caso de eventuais dúvidas. No início de minhas visitas ao campo, eu mesma 
preenchi uma dessas decisões a pedido da secretária. Curiosa, folheei o processo. Era um caso sobre o furto qualificado de uma bicicleta. A defesa pedia a liberdade provisória do réu baseada na primariedade do autor do crime. Perguntei à Sandra o que deveria fazer. "O modelo pra liberdade provisória tá na pasta de decisões interlocutórias", me respondeu. Eu sorri enquanto pensava sobre respostas irônicas que, obviamente, não foram verbalizadas. O que eu realmente esperava saber é se deveria conceder ou não a liberdade provisória do réu, já que não recebera orientação nesse sentido. Porém, depois de explorar a pasta e os arquivos com um olhar mais paciente e apurado percebi como minha pergunta era ridícula. Não havia nenhum modelo de concessão de liberdade provisória na pasta.

Ao longo do trabalho de campo, interagindo com a juíza e os outros interlocutores do gabinete, eu compreendi que as decisões sobre os casos são tomadas antes mesmo dos fatos serem denunciados. Manifestamente antes mesmo até de os fatos acontecerem, como passo a expor na sequência. Por isso entendo que incide sobre a dinâmica decisória do gabinete um fenômeno que classifico como procedimentalização.

A juíza decidiu há alguns anos sobre o fluxo decisório no gabinete, pelo qual nenhum réu pode ser absolvido sumariamente ${ }^{2}$ ou ter uma medida cautelar diversa da prisão aplicada durante o período que compreende a denúncia (ou prisão em flagrante) e a sentença. Ou seja, ainda que a defesa do réu apresente na Resposta à Acusação ${ }^{3}$ um pedido de absolvição sumária corroborado por evidências robustas demonstrando que ele não estava presente no local do fato, prevalece a regra da prisão e da presunção de culpa.

Em um caso de roubo no qual não houve flagrante, mas reconhecimento em sede policial no "livro de suspeitos", a defesa apresentou um pedido de absolvição sumária do réu, demonstrando que ele estava em outro estado no dia dos fatos. Além de indeferir o pedido, a

2 No procedimento comum ordinário, o art. 397 do CPP prevê a possibilidade de absolvição sumária do acusado, ou seja, um julgamento antecipado da lide penal, quando o juiz verificar a existência manifesta de causa excludente da ilicitude do fato; a existência manifesta de causa excludente da culpabilidade do agente, salvo inimputabilidade; quando o fato narrado evidentemente não constitui crime; ou quando extinta a punibilidade do agente.

3 A resposta à acusação é o meio processual de defesa do denunciado preliminar confeccionada após o recebimento da denúncia pelo juízo e citação do denunciado para respondê-la, devendo fazê-la por escrito e no prazo de 10 dias, segundo os termos dos artigos 396 e 396-A do Código de Processo Penal. Conforme observei no campo, a peça é usada por advogados para apresentar pedidos de absolvição sumária e de liberdade provisória. Trata-se de uma peça processual de no máximo duas folhas que também vem acompanhada de um rol de testemunhas que quase sempre são fictícias. Raramente a peça aventa teses defensivas.

4 Trata-se de uma modalidade de reconhecimento difundida pela Polícia Civil do Rio de Janeiro que consiste em fotografar indivíduos presos em flagrante e acrescentar sua foto a um livro. Sempre que alguém chega à delegacia para registrar um crime em que não houve flagrante, o livro é apresentado para identificação de um dos indivíduos previamente fotografados. Essa forma de ingresso dos fatos no sistema foi muito recorrente no campo da justiça criminal na Baixada Fluminense. 
prisão preventiva decretada no momento da apresentação da denúncia do Ministério Público foi mantida. Essa lógica é norteada pelo entendimento da juíza de que o momento oportuno para conhecer os fatos é a Audiência de Instrução e Julgamento. Por conta disso, o único contato dela com o caso anterior à fase do ritual das audiências, se resume a assinar, mecanicamente, os documentos das decisões e despachos confeccionados pelos outros profissionais do gabinete.

Assim, o fluxo processual padrão dentro do gabinete procedimentaliza a presunção da culpabilidade. Sempre que uma denúncia é apresentada, esse ato processual que abre prazo para que a defesa apresente Resposta à Acusação é acompanhado da aplicação da pena restritiva de liberdade. Mesmo se o Ministério Público não apresentar o pedido da prisão cautelar, o modelo de recebimento da denúncia contém a decretação da prisão preventiva do réu. Até porque quando os atos seguem o fluxo processual, não há uma leitura atenta das petições apresentadas pelas partes, o que põe em ainda mais evidência a procedimentalização desses atos.

Sobre o assunto das prisões preventivas, a juíza me explicou que não decreta liberdade provisória de nenhum réu porque caso seja culpado "ele irá sumir no mundo". Segundo ela, é praxe de outros magistrados conceder a liberdade provisória para pessoas que sejam réus primários, apresentem comprovante de residência e de vínculo profissional. Mas para a juíza, esses elementos não garantem que a persecução penal não perecerá. O diálogo a seguir, evidencia tal percepção.

— Essa gente chega aqui com comprovante de residência da vivo, pede pro padrinho que tem uma vendinha na esquina assinar a carteira de trabalho. Depois a gente manda soltar e some no mundo, não tem mais notícia, não localiza nunca mais. Essa gente não tem raízes, não tem conta em banco, não tem cartão de crédito. Como faz pra prender de novo? E aí como fica a resposta que a gente precisa dar pra sociedade pelo crime que ele praticou?

- Isso em todo tipo de crime?

- Sabia que você ia perguntar isso. - Risos. - Vou te contar uma coisa. Eu já fui muito criticada alguns anos atrás dentro do TJ porque mantive a prisão preventiva de uma mulher que furtou uma farmácia e levou duas latas de leite escondidas numa bolsa plástica de mercado. A decisão foi reformada até no STJ. Meus colegas, até amigos próximos, me criticaram muito. Mas ninguém pensa do meu ponto de vista. Se a gente deixa essa senhora livre e ela não aparece nunca mais... como fica? Vai ter mandado de prisão aberto contra ela por longos anos. Vai atrapalhar a vida dela mesma se isso acontecer. No fim das contas, ela fica preventivamente, pega uns meses de prisão enquanto aguarda o julgamento do processo e pode ser absolvida no final da instrução. Pronto. Sem contar que ela disse que era pro filho e etc. e tal. Mas quem garante que ela tem mesmo filho? Não podia tá levando o raio do leite pra revender em algum camelô da vida? Há muitas versões sobre o mesmo fato e a gente só tem contato com os fatos na AIJ.

- Claro, faz sentido seu ponto de vista. Mas a gente escuta tanto falar sobre 
casos em que a pena aplicada é até menor do que o tempo que a pessoa ficou presa preventivamente...

- Acontece sim! Principalmente em crimes de furto, se o réu for primário a pena vai lá embaixo e condena direto no aberto ou semiaberto. Mas aí você me responde. Essa mulher da lata de leite, ela não praticou um crime? Praticou, gente! Ela pode até estar amparada por uma excludente de ilicitude, mas o procedimento penal vigente no Brasil só autoriza a gente a avaliar essas questões depois de conhecer os fatos, no momento da sentença.

- Mas e se o sujeito for mesmo inocente?

—É a mesma linha de raciocínio. Se ele for inocente vai ser absolvido no final do processo. Aí é a vida, é o preço que se paga por viver em sociedade, por viver sob os olhos da lei. Mas nunca é. Eu diria que em... não sei... 99,9\% dos casos? Eles são sempre culpados! (Notas do Caderno de Campo - Diálogo com Juíza Titular - Vara Criminal).

Com relação aos casos de flagrante delito, que são notavelmente a maior parte dos processos que circulam na Vara Criminal, a juíza, mais recentemente, adotou outro procedimento no que se refere à decisão sobre pedidos de liberdade. Devido à implementação do instituto das audiências de custódia, ela passou a adotar o entendimento de que a decisão sobre a conversão da prisão em flagrante em preventiva deixou de ser sua responsabilidade. Assim, quando um novo flagrante é recebido pelo juízo, não há nenhuma alteração daquilo decretado na audiência cautelar, ainda que tenha sido determinada a liberdade provisória do réu, não há uma nova análise do mérito da prisão. O conteúdo do modelo nominado liberdade provisória_custódia se resume em uma linha "mantenho a decisão da Audiência de Custódia, pelos fundamentos lá expostos".

Sapori (1995) identificou um paradoxo próprio da justiça criminal brasileira que ele identificou como linha de montagem. Para o autor, o sistema brasileiro é completamente formalizado e dotado de uma complexa estrutura burocrática, mas na prática revela informalidades institucionalizadas na Justiça Criminal. Na medida em que a meta da eficiência supõe a busca da maximização da produção num curto intervalo de tempo, através da informalidade, levam a uma violação informal das normas e do devido processo legal. Assim, a criação de padrões de julgamento encaixa casos concretos a resultado antevistos, sem uma análise detida de cada caso, uma vez identificados padrões previamente conhecidos sobre os quais se opera uma solução também previamente conhecida.

A categoria analítica construída pelo autor retoma a análise criminológica feita por Blumberg (1967) em alusão ao modelo de produção empregado pela indústria fordista no século XX. O termo, portanto, é utilizado no sentido de caracterizar a dimensão da padronização em larga escala, observando que a justiça se vale desse mecanismo para processar e julgar, de 
maneira ágil e pouco reflexiva. Weber (1999) já percebia a burocracia como a forma mais eficaz de conduzir as demandas de velocidade, precisão e impessoalidade no âmbito desse modelo de produção capitalista, fundamentada nos ideais liberais e republicanos de isonomia e legalidade. Isso porque o conceito de burocracia agrega como valores o formalismo, a hierarquia, a impessoalidade e a documentação, sendo caracterizado pela existência de hierarquia nos quadros administrativos e prevalência de documentos escritos.

Apesar das categorias construídas pelos pesquisadores auxiliarem na reflexão sobre os fluxos processuais, elas não alcançam completamente a análise daquilo que observei no campo da Baixada Fluminense. As linhas de montagens que respondem aos padrões norteados pela informalidade consistem numa atuação que denota improvisos, com o objetivo de que tempo e volume sejam mitigados. Assim, a meta de eficiência da linha de montagem é "zerar" o número de processos. Por isso, o estabelecimento desses padrões é norteado pelos princípios burocráticos aplicados no contexto brasileiro sem compromisso com a racionalidade. Contudo, no contexto que observei, os padrões e modelos não se esgotam em si mesmos. Além disso, são mobilizados com objetivos direcionados.

Embora eu também tenha identificado no campo da Baixada Fluminense uma linha de montagem processual em pleno vapor - fenômeno evidenciado no ir e vir de documentos e pelo preenchimento padrão de papéis mecanicamente assinados e juntados aos processos - percebo nessa dinâmica mais do que um movimento que remonta o clássico de Charles Chaplin. Isso porque a padronização das decisões tem por objetivo possibilitar a concretização do elemento punitivo inerente ao direito penal e reproduzir, fase após fase, aquilo reduzido a termo em sede policial. Por isso, não é uma sequência desconexa, já que destinada a um objetivo final. A produção de decisões em escala padronizada se revela naquele lugar como uma técnica empregada para preservar a presunção de culpabilidade (FERREIRA, 2013) e viabilizar a execução antecipada do elemento aflitivo inerente à pena (FOUCAULT, 1999).

Há certa ênfase na construção progressiva da culpabilidade do acusado em nossos sistemas de segurança pública e judicial, construção anterior ao julgamento do caso pelos juízes (FIGUEIRA, 2008), já que o indivíduo que é pego pelas malhas do sistema de segurança pública e recebe, ao longo dos procedimentos legais, as denominações de indiciado com a abertura do inquérito policial pelo delegado de polícia, de denunciado com a acusação formal do promotor de justiça, de réu com o recebimento, pelo juiz de direito, da denúncia. Por essa razão, a defesa precisa apresentar estratégias e/ou performances melhor desenvolvidas para reconstruir essa presunção de culpabilidade sobre o réu, algo que só é passível de se concretizar em casos excepcionais, conforme demonstrarei a seguir. Portanto, as decisões são procedimentalizadas para 
dar lugar a fins específicos, orientados por um processo de sujeição criminal (MISSE, 2008). A construção dessa dinâmica só é possível porque nela opera diretamente a concepção moral dos atores (EILBAUM, 2010) que detém o poder decisório no âmbito do caso concreto.

\section{PRODUZINDO SENTENÇAS: CASOS SEMELHANTES E CASOS EXCEPCIONAIS}

A maior parte do trabalho de campo que realizei na Baixada Fluminense aconteceu numa dinâmica interativa entre os espaços do gabinete e da sala de audiência da Vara Criminal de titularidade da juíza. Minha descrição prioriza o gabinete na ordem de apresentação dos dois cenários porque observei um ponto crucial para compreensão do fenômeno de julgar naquele espaço, tanto no que se refere aos casos de tráfico de drogas, fio condutor da observação, como aos demais casos objetos de julgamento. Diferentemente daquilo que orientava minhas reflexões (e até o meu olhar) antes de ir ao campo - por uma ordem lógico-cronológica do procedimento processual penal - os julgamentos sobre os casos não são formulados durante ou após o ritual da Audiência de Instrução e Julgamento. Ao contrário, percebo uma máxima que se reitera e opera sobre as sentenças o efeito da padronização do julgamento de casos semelhantes.

Conforme expliquei anteriormente, é parte da atuação profissional dos assistentes da juíza redigir as sentenças. Em termos práticos, isso significa que eles buscarão dentre os modelos, sentenças semelhantes anteriores de casos semelhantes para fundamentar os argumentos decisórios. A partir daí as partes da sentença vão sendo preenchidas usando o método "copia e cola", orientado pelas particularidades dos fatos apresentados durante todo o procedimento de persecução penal. Os modelos de sentença diferem consideravelmente dos modelos de decisões quando avaliados em extensão e conteúdo. Enquanto as decisões e despachos costumam ter, quando muito, duas laudas, alguns modelos de sentença têm mais de 30 páginas corridas.

Sandra preenchia os seus projetos de sentença em partes. Ela abria o documento de um modelo de sentença de um caso a partir de um caso semelhante àquele. Então ela colava os fatos da assentada da audiência que ela mesma redigiu; em seguida, folheava brevemente o processo para buscar por informações negligenciadas no relatório da AIJ. Depois partia para o preenchimento da parte final da sentença sobre o julgamento do pedido do Ministério Público em si (se procedente ou improcedente), calculando o quantum da pena. Finalmente, Sandra relia os fundamentos daquilo que sentenciou, retirando ou acrescentando argumentos que melhor se 
adequavam aos fatos e ao julgamento do caso.

É interessante observar que a peça denominada Alegações Finais por Memoriais, apresentada tanto pela defesa quanto pela acusação após a Audiência de Instrução e Julgamento de forma escrita, não é lida na integralidade pelos assessores. Muitas vezes sequer é consultada. Quando da produção da Sentença, a verificação da peça do Ministério Público visa diretamente à página que contém os pedidos. $\mathrm{O}$ objetivo é identificar em quais artigos foi requerida a condenação dos réus, para então reproduzi-los na condenação.

A peça da defesa, por sua vez, é ignorada. De modo que os argumentos fáticos e jurídicos são assimilados por esses profissionais tão somente no momento da audiência. A secretária explicou que não precisa ler a peça da defesa porque já sabe quais teses serão apresentadas, já que no ato da audiência os advogados deixam evidentes quais estratégias irão utilizar.

A gente já sabe o que os advogados vão falar. Fica tudo muito claro na audiência. A própria juíza já sabe, já seleciona os processos que podem fugir dessa regra. Não vale à pena ler. É perda de tempo. No caso de tráfico, por exemplo, eles vão dizer que foi tudo forjado, que não tinham droga, que são usuários, que foram confundidos, que a droga era de outra pessoa, que tá sendo perseguido etc., etc., etc. Tudo o mesmo blábláblá. (Notas do caderno de campo).

Além disso, Márcio também chamou a minha atenção para o fato de que os modelos também são amplamente utilizados pela defesa:

Eles ajustam os fatos aos modelos deles. A defensoria a gente nem olha mesmo, porque são sempre os mesmos modelos. Eles (os defensores) compartilham. Quando é advogado particular eu às vezes folheio pra ver se alguém usou um novo entendimento do TJ ou do STJ, qualquer coisa assim, recente, sabe? Até alguma novidade do STF. Nada. A maioria é modelão de internet mesmo. Vira e mexe colocam coisa desatualizada, de 1900 e tal. Tem uns que fundamentam com os julgados de outro estado, do Rio Grande do Sul aparece muita coisa. Tudo por causa dos modelos que eles pegam por aí, sem nem conferir. (Notas do caderno de campo).

Muito me surpreendeu quando Márcio explicou que o mais trabalhoso na elaboração da sentença não é o fundamento da decisão, mas o relato dos fatos. É que a fundamentação de todos os casos é igual, uma vez que mobilizam argumentos doutrinários e jurisprudências idênticos, que antecedem o conhecimento e assimilação dos fatos a serem julgados.

No início da pesquisa, com o intuito de formular uma situação problema para o trabalho de tese de doutorado, analisei os argumentos decisórios das sentenças sobre drogas e identi- 
fiquei a reprodução de toda discussão jurisprudencial que fundamenta a Súmula 70 do TJ/RJ (GARAU, 2015). Naquele momento, direcionei o meu olhar para a hipótese que respondia a problemática inicialmente proposta, no sentido de que o testemunho policial militar é central na decisão do juiz. Ora, uma vez que os dispositivos fundamentadores dessas sentenças frequentemente faziam referência à fé pública policial e à presunção de veracidade de seus respectivos depoimentos, bem como ao vocabulário de motivos que evocam elementos da rotina e experiência policial (JESUS, 2016), concluí naquele momento sobre a centralidade do testemunho policial nas sentenças sobre processos de tráficos de drogas.

Entretanto, a partir da dinâmica que conheci no gabinete, refletindo sobre o contexto de preenchimento dos modelos com o qual me deparei no campo da Baixada Fluminense, reflito sobre as considerações de Eilbaum (2008) quanto à justiça argentina e brasileira. A antropóloga identificou o caráter predominantemente formal da administração da justiça, na qual os fundamentos das decisões não refletem as motivações fáticas, a partir da noção de que a forma prevalece sobre o fundo (conteúdo) (RENOLDI, 2008). Neste sentido, produz-se um tipo de conhecimento formalizado, descontextualizado e despersonalizado. Isso significa que, diferentemente daquilo que se tem como representação e expectativa legal/social do ato de julgar, o conteúdo das sentenças está atrelado a um modelo que encontra na forma a capacidade de validação do julgamento pela própria forma.

Desse modo, assumo que os argumentos utilizados nas sentenças de tráfico de drogas, bem como dos demais tipos penais, são apresentados como fundo quando na realidade são apenas a forma. Isso porque o processo decisório em si é produzido em virtude da forma. $\mathrm{O}$ que quero dizer é que o testemunho policial, a título de conteúdo, tem pouca (ou até nenhuma relevância) durante a produção do conteúdo da atividade decisória; ao contrário, visa embasar argumentos que se apresentam formalmente aceitáveis dentro da estrutura processual, emoldurados por uma série de discursos jurídicos que remontam a simbologia do campo jurídico (doutrina e jurisprudência).

A construção prévia dos argumentos basilares da condenação são, portanto, parte do fluxo procedimental que orienta o funcionamento da própria justiça criminal, naquilo definido por Kant de Lima (1999) como um mosaico de sistemas verdades, conformado a partir de procedimentos diferenciados de produção da verdade (que operam desde a fase pré-processual). Tais argumentos, por sua vez, são determinados pelos policiais e operadores do direito a partir de uma série de depoimentos que reforçam, progressivamente, a rotulação inicial de alguém pela prática de um fato classificado como delito. Nesse ponto, a verdade produzida pela polícia é a responsável por transformar o crime em uma realidade, pois, a partir da incriminação de 
alguém como suposto criminoso, ela se torna mais viável.

Portanto, são os casos semelhantes que organizam e orientam a dinâmica de julgar do gabinete. Mobilizo a categoria casos excepcionais, em contraste aos casos semelhantes. Entretanto, não como um mero sinônimo daquilo tachado como casos corriqueiros ou de rotina, mas no sentido de chamar a atenção para o fato de que sobre os casos semelhantes prevalece a máxima da presunção de culpabilidade (FERREIRA, 2013), orientada desde o início pela procedimentalização dos atos que antecedem a fase de conhecimento e julgamento. Isso se consolida num processo que conjuga o elemento da sujeição criminal (MISSE, 2008, 2010) operacionalizado dentro de um sistema de justiça criminal que valoriza práticas inquisitoriais que partem da desigualdade de indivíduos na hierarquia social (KANT DE LIMA, 1997).

O referencial de semelhança parte do delito no qual foi tipificada a conduta do réu, ou seja, da conotação jurídica que emoldurou os fatos praticados pelo acusado, tornando-o factível para o mundo jurídico (JESUS, 2016). Por isso, o dispositivo penal sob o qual se deu o processo de criminação supõe a interpretação de um evento singular enquanto crime, enquadrando-o na classificação criminalizadora de uma ação, e a mobilização de todos os procedimentos que farão do evento um "crime" do ponto de vista legal. Esse processo de criminação não se reproduz apenas pela adequação de fatos a um tipo penal, ele só se consolida a partir do momento que os fatos são traduzidos em procedimentos escritos (PAES, 2010).

Assim sendo, a forma como o crime será administrado abrange um tipo de performance que age de forma diferenciada sobre o fato e o autor. Nas condutas envolvendo tráfico de drogas, há uma atuação diferenciada no que se refere ao tratamento procedimental dos crimes de uso e ao tráfico de entorpecentes. Da mesma forma, a figura de tráfico de drogas difere daquela que refere à associação ao tráfico de drogas. Entretanto, essa classificação não produz efeito apenas do ponto de vista do dever ser mas, ao contrário, mobiliza práticas e ferramentas diferenciadas de julgar os fatos e o autor desses fatos.

Os crimes processados e julgados pela Vara Criminal são eminentemente de natureza patrimonial: roubo, furto e receptação. Somam-se a essas modalidades delitivas a expressiva quantidade de crimes de drogas, em sua maioria tráfico de drogas e associação para o tráfico de drogas. Outros delitos frequentes, comumente atrelados aos casos de roubo e de drogas, são os crimes do Estatuto do Desarmamento que dispõe sobre o porte de armas.

Porém, a característica comum da criminação não caracteriza por si só um caso semelhante, quando desacompanhada da sujeição criminal (MISSE, 2008). Isso porque, para além da figura típica sobre a qual foi emoldurada a conduta do réu, todo fluxo processual é conduzido com base na identidade virtual dos indivíduos (GOFFMAN, 2011), uma vez que se referem não 
apenas aos rótulos e à identidade social desacreditada dos sujeitos (como no estigma), mas à incorporação de papéis e de carreiras criminosas. A sujeição criminal realiza a fusão plena do evento com o ator, mesmo nos casos em que o evento não se efetiva, sendo somente potencial. Nessa dinâmica, há um processo de subjetivação que segue o curso de internalização do crime no sujeito que o suporta e que o carrega como um "espírito" que tomou conta do corpo e da alma (MISSE, 2008). Quero dizer que sobre esses indivíduos se opera uma seleção dos supostos sujeitos que irão compor um tipo social cujo caráter é socialmente considerado como "propenso a cometer um crime".

No que se refere às práticas que procedimentalizam a presunção de culpa do réu, o racismo institucional encontra amparo dentro dessa dinâmica, assim como maior espaço para consolidação. No Brasil, as instituições que operam nas fases anteriores ao oferecimento da denúncia atuam norteadas por referenciais que replicam práticas racistas (MEDEIROS, 2018; MONTEIRO, 2003). O estereótipo do negro morador de favela associado à criminalidade, influencia na tomada de decisões das organizações de segurança pública, algo que reflete diretamente no encarceramento em massa (SINHORETTO; GIANI, 2014, ALEXANDER, 2017; BORGES; VINUTO, 2020). Não por acaso, 77,4\% dos presos em flagrante apresentados para audiência de custódia, entre setembro de 2017 e setembro de 2019, no Rio de Janeiro eram pretos ou pardos 5 .

Assim, não há por parte dos membros da família judicial um processo racional que problematiza a prevalência de determinados perfis assentados à cabeceira da mesa nas salas de audiências criminais da justiça carioca. Por isso, a dimensão do racismo institucional está nas práticas dos atores com os quais interagi ao longo do trabalho de campo, expressa na procedimentalização, já que os operadores naturalizam todas as etapas que prescindem a formulação da culpa do sujeito.

Recentemente uma juíza do Paraná condenou um homem negro a 14 anos de reclusão por integrar uma organização na capital do estado. O caso ganhou repercussão midiática porque no texto de fundamentação da sentença, a juíza responsável pelo julgamento fez menção ao tom de pele do réu ao afirmar "seguramente integrante do grupo criminoso em razão de sua raça"6. No caso em questão, a julgadora tão somente explicitou algo naturalizado pelo judiciário, uma lógica que caminha às sombras da forma como são processados e julgados casos criminais, já

5 Relatório da Defensoria Pública do Estado do Rio de Janeiro sobre as Audiências de Custódia. Disponível em: http://www.defensoria.rj.def.br/uploads/arquivos/0b6d8d161c1b41739e7fc20cca0c1e39.pdf. Acesso: 25 ago. 2020.

6 Disponível em: https:/g1.globo.com/pr/parana/noticia/2020/08/12/juiza-diz-em-sentenca-que-reu-negro-era-seguramente-integrante-de-grupo-criminoso-em-razao-da-sua-raca.ghtml. Acesso em: 12 ago. 2020. 
que a prática decisória é insubmissa às regras implícitas na qual o objetivo é desembaraçar o conjunto de registos que constitui o processo (GERALDO; RAMOS, 2020).

A análise dos casos semelhantes ganha mais sentido quando em contraste aos casos excepcionais. Quando há rompimento de expectativas prévias com relação ao delito (processo de criminação) e ao delinquente (processo de sujeição criminal), os casos semelhantes dão lugar aos casos excepcionais. Cumpre ressaltar, antes de aprofundar a diferenciação das categorias, que no contexto do campo de pesquisa, todos os casos são tratados como semelhantes nas fases que antecedem a formulação da sentença, numa expressão daquilo apresentado como procedimentalização. O momento processual que tem potencial de ensejar a identificação de um caso excepcional, é a Audiência de Instrução e Julgamento.

Isso porque, embora o ritual da audiência também tenha como ponto de partida a procedimentalização, o contato da juíza com as identidades de todos os atores do processo pode provocar as suas moralidades (EILBAUM, 2010), e, portanto, têm potencial de desconstruir a identidade do sujeito criminal, inviabilizando a incriminação desse sujeito. Inclusive, a principal característica prática dos casos excepcionais é exatamente o fato de que o modelo de sentença não será a base para o ato de julgar. A sentença não será preenchida pelos assessores, mas construída pela própria juíza.

Isso ocorre porque nos casos excepcionais o julgamento não é anterior ao conhecimento dos fatos. Ao contrário, o ato de decidir passa a ser resultado de formas de categorização de relatos, eventos e tipos sociais apresentados às partes envolvidas no processo de tomada de decisão (GERALDO; ALMEIDA, 2017). Assim, o novo processo decisório incide de forma diferenciada sobre os casos excepcionais. De modo que a sentença não é a mera reprodução de outros casos semelhantes, mas a construção de uma nova categorização do ato de julgar.

Por isso, o primeiro ponto para a classificação de um caso excepcional é o tipo penal sob o qual incidiu o processo de criminação. Um caso específico sobre pedofilia, por exemplo, foi identificado pelos interlocutores como caso excepcional. Quando a juíza se deparou com a tipificação do crime ao consultar a pauta das audiências do dia, o imaginário dela foi mobilizado por suas próprias moralidades. Ela fez alusão à repulsa e hostilidade desse tipo de crime e referência à preocupação com a imagem social do sujeito condenado por esse tipo de crime: "é muito grave, precisa ser analisado com cuidado, isso pode destruir a vida de uma pessoa". Anunciando assim, antes da audiência começar, que seria a responsável pela sentença daquele caso.

Conforme especifiquei anteriormente, a maior parte dos processos que acompanhei tratam de fatos classificados como roubo (nas mais diversas modalidades), tráfico e associação 
para o tráfico de drogas, furto, porte ilegal de arma de fogo, receptação e estelionato (nessa exata ordem de prevalência). Ao longo de oito meses pesquisando na Vara Criminal da baixada, tive contato com mais de 250 casos $^{7}$, considerando autos processuais e audiências ${ }^{8}$. Outros tipos penais são absolutamente raros. Pouquíssimos casos estavam tipificados de forma diversa. Estupro de vulnerável, injúria racial qualificada por raça, uma vez cada. Lesão corporal, meia dúzia de casos. Maus-tratos contra animais, um caso distribuído equivocadamente para a Vara Criminal, ao invés do Juizado Especial Criminal. Esses foram todos os casos excepcionais com relação ao processo de criminação, revelando a prevalência de tipos criminais específicos.

O segundo grupo de casos que classifico como excepcionais está relacionado com a forma de ingresso dos fatos no sistema de justiça. Casos oriundos de flagrante delito, quando não operou sobre eles o processo de criminação que lhes atribui a característica dos casos excepcionais, são sempre casos semelhantes. Enquanto casos resultantes de ações não flagrantes ou investigação criminal são casos excepcionais. Isso ocorre por conta da centralidade do flagrante na tradição jurídica brasileira (ADORNO; PASINATO, 2010).

Finalmente, a terceira modalidade está atrelada ao tipo de moralidade atribuída à prova produzida. Esse terceiro aspecto mobiliza mais intimamente as subjetividades da julgadora, já que há o rompimento de expectativas com relação às identidades dos atores criminais que atribuem sentido aos fatos objeto de julgamento. Assim, a presença de vítimas, por exemplo, e o depoimento de policiais militares caracterizam casos semelhantes. Isso se revela como parte essencial da dinâmica de presunção de culpa dos sujeitos, reforçada pela fé pública (ALMEIDA JÚNIOR, 1920) atribuída a todos os documentos oriundos do cartório (MIRANDA, 2000; VIDAL, 2013).

Entretanto, casos que mobilizam elementos probatórios acidentais podem converter-se em casos excepcionais a partir do rompimento de expectativas com relação às identidades dos atores do processo, incluindo-se aqui defesa e acusação, bem como testemunhas de defesa, réus, vítimas e testemunhas de acusação. Em um caso que acompanhei e denominei "11 bandidos e o militar", todas as suas características até a Audiência de Instrução e Julgamento

7 Não tenho a pretensão de explicitar números exatos, pois a metodologia empregada na análise dos dados não foi direcionada a levantamentos quantitativos, porém, a enorme prevalência desses tipos penais em detrimento de quaisquer outros é um elemento qualitativo relevante com relação ao campo, demonstrando as moralidades mobilizadas pelos atores responsáveis pela filtragem dos casos, que, por sua vez, é reiterado pelos fluxos processuais e pela procedimentalização, operacionalizada no âmbito do judiciário.

8 Ressalto a diferença entre ambos os espaços, pois o tempo processual é diferente em cada um deles. Descreverei isso mais detidamente na próxima seção, porém, por ora, cabe a informação de que por cartório e audiência operarem sobre tempos processuais distintos, por isso tive contato com casos em fases distintas. 
lhe dava a aparência de caso semelhante. O caso envolvendo o sequestro de um ex-policial militar que reconheceu em sede policial todos os réus do processo como integrantes da facção local. Todavia, um dos acusados era militar do exército e a mobilização da identidade desse réu por parte da defesa estendeu a todos os outros a absolvição pelos fatos, transformando-o assim em um caso excepcional.

\section{O RITUAL DAS AIJ COMO PARTE DA PROCEDIMENTALIZAÇÃO PELA MERA FORMALIDADE}

Ao acompanhar as audiências nessa Vara Criminal, percebi que o fazer judicial também está atrelado à noção de procedimentalização. Ou seja, da manutenção do status quo do processo, no qual a presunção de culpabilidade do réu se reproduz. A lógica restou evidente em uma audiência de cumprimento de carta precatória para oitiva de uma vítima que teve sua moto roubada em São Gonçalo. Muito tempo depois da ocorrência, o réu foi acusado do crime de receptação ${ }^{9}$ da moto que foi apreendida durante uma incursão da Polícia Militar na cidade para apreensão de drogas. Ou seja, o homem era réu na Comarca de São Gonçalo pelos crimes de tráfico de drogas e receptação. Assim, estava sendo acusado pela receptação da moto e não pelo roubo.

O pedido do juiz de São Gonçalo era que a comarca da Baixada conduzisse e registrasse o procedimento de oitiva do depoimento da vítima, considerando as circunstâncias em que o crime de roubo aconteceu. Quando a juíza determinou o reconhecimento pessoal do acusado, a advogada protestou: "Excelência, ele está sendo acusado de receptação; esse ato é só uma formalidade pra demonstrar no processo originário que o bem de fato havia sido roubado, não há acusação de roubo contra esse réu". A juíza respondeu, de forma impaciente e autoritária: “Aqui as coisas funcionam assim. Vai que ele ainda leva pra casa um roubo de brinde?! Maravilhoso, doutora, você ainda vai poder cobrar mais caro pelo trabalho".

Observei nesta dinâmica de reconhecimento pessoal do réu, a presunção de culpabilidade dos sujeitos criminais naquele espaço, ainda que, tal qual no caso exposto, não seja o crime

9 Crime previsto no Código Penal, Art. 180 - Adquirir, receber, transportar, conduzir ou ocultar, em proveito próprio ou alheio, coisa que sabe ser produto de crime, ou influir para que terceiro, de boa-fé, a adquira, receba ou oculte: Pena - reclusão, de um a quatro anos, e multa. 
objeto do processo. Isso acontece porque há uma construção progressiva da culpabilidade do acusado no sistema de justiça criminal.

Houve muitas situações, nas audiências de casos de tráfico de drogas, em que os policiais não compareciam em juízo para prestar depoimento. Não obstante, os acusados eram igualmente culpabilizados, em virtude de dinâmicas anteriores que conferiam verossimilhança às inculpações. A ocorrência foi constante tanto no campo da Baixada Fluminense quanto na parte da pesquisa que desenvolvi em outras comarcas do Rio de Janeiro. Os policiais faltavam as audiências com frequência, não raramente, mais de uma vez para um mesmo caso. Num processo em específico, a Audiência de Instrução e Julgamento foi remarcada três vezes porque um dos policiais não compareceu à juízo. Apesar de o primeiro policial ter apresentado seu testemunho, a juíza optou pela preservação da prova, insistindo no comparecimento do segundo policial. Na terceira ocasião, meses após a primeira tentativa, a juíza finalmente dispensou a testemunha, atendendo ao pedido que já havia sido formulado pela defesa - e indeferido sob o argumento de indispensabilidade da prova - nas audiências antecedentes. Em momento posterior a despeito da ausência da prova, minha interlocutora sentenciou o réu à condenação, tal qual também faria se tivesse ouvido o agente policial, visto que esse é o entendimento do juízo para casos semelhantes de tráfico de drogas.

Compreendi que, no caso concreto, a presunção de culpabilidade acompanhou toda a audiência, e a ausência de um dos policiais militares não foi percebida pela juíza como um prejuízo aos direitos e garantias do acusado, mas, antes, como um prejuízo à construção dos argumentos formais que permitiriam a fundamentação formal da condenação do réu, por isso a insistência na oitiva.

Observo uma dinâmica que perpassa a fase processual das audiências de instrução e julgamento, dando lugar a atos que são cumpridos por mera formalidade, tal como relatado por Eilbaum (2012) quando participou, na condição de testemunha, de um Juicio Oral em La Plata na Argentina. A ênfase da expressão foi identificada por ela como a excepcionalidade de ouvir testemunhas que não pudessem falar sobre as circunstâncias dos fatos. É que a antropóloga estava ali na condição de testemunha técnica para apresentar o estudo comparado que havia realizado no contexto do Brasil e da Argentina. Ocorre que a autora identificou um incômodo dos operadores com relação à sua presença já que, uma vez que não tinha relação com o caso, ela não se expressava na linguagem jurídica para aportar elementos técnicos. Portanto, não atendia às expectativas dos interlocutores para contribuir de maneira a compor adequadamente o cenário no qual se constroem os procedimentos de aferição da culpabilidade dos sujeitos envolvidos no caso sob julgamento. 
No contexto de meu campo na Baixada Fluminense, identifico que por parte da família judicial (NUÑEZ, 2018; SARRABAYROUSE, 1998) há uma espécie de incômodo pairando no ar sempre que aqueles que não fazem parte dessa família entram na cena da audiência. Isso acontece porque todos os atos da audiência, naquele contexto, são conduzidos pelos seus integrantes por mera formalidade. A denúncia é lida só por formalidade; as testemunhas policiais, de igual modo, são recebidas por formalidade. O réu, quando fala, também é ouvido de acordo com esse registro. Há um consenso que perpassa a relação entre os promotores, a magistrada e a defesa pública, no sentido de que tais atos são formalidades que conduzem à condenação.

Essa juíza é linha dura. Não vale a pena se desgastar muito porque a condenação vem. Ainda mais nos casos de flagrante...Ela condena mesmo, sem pena. Pode ser trabalhador, pode ser pai de família. Se foi pego em flagrante ela não quer nem saber. Agora, se chega aqui um caso todo zoado, um flagrante duvidoso... sei lá, uma história que me convence, sabe? Eu até tento mudar alguma coisa. Tento construir uma versão que convença. Por exemplo, se eu vejo que a vítima chegou aqui e não reconheceu o réu, eu não vou ficar calado, né? Tenho que fazer o meu trabalho. Tenho que tentar mostrar pra juíza que naquele caso tem alguma coisa errada. Aí eu mando falar, às vezes até eu mesmo já falo na audiência mesmo "olha, não reconheceu o réu". (Notas do caderno de campo - fala de um defensor público da Comarca)

Quando alguém de fora da família judicial entra, inadvertidamente, em cena a condução protocolar, formal, dá lugar à lógica do contraditório (KANT DE LIMA, 2010). Ou seja, um processo em que aqueles que conduzem o formalismo do rito buscam desqualificar as teses presentes no argumento alienígena, não permitindo que ele componha o enredo da verdade a ser construída sobre o caso. Cabe ressaltar que isso não significa que a defensoria abre mão do contraditório, mas apenas que o fará em outro momento oportuno, na apresentação das Alegações Finais. Entretanto, no ato da audiência a apresentação das teses por essas partes está destinada unicamente a cumprir uma nova etapa do procedimento, já que para esses atores é mais claro que a decisão final se baseia exclusivamente no convencimento do julgador (MENDES, 2011). Os advogados particulares, por outro lado, estão empenhados em convencer a juíza sobre um outro ponto de vista, na esperança de descontruir as presunções inerentes a todas as fases que antecederam o momento da audiência, ou seja, conduzir o olhar dos magistrados quando de um caso semelhante para um olhar de caso excepcional. Na maioria das vezes sem o efetivo sucesso. 


\section{CONSIDERAÇÕES FINAIS}

Conforme demonstrei neste artigo, os atores que atuam no gabinete são os responsáveis pela confecção dos documentos mais relevantes do processo: as sentenças e decisões. As atividades desses atores, que praticamente remontavam um modelo fordista de produção, estavam centradas no preenchimento de modelos e decisões previamente construídas que não consideram o caso concreto em si, senão casos semelhantes. Ao longo do trabalho de campo, interagindo com a juíza e os demais interlocutores do gabinete, eu compreendi que as decisões sobre os casos são tomadas antes mesmo dos fatos serem denunciados. Manifestamente antes mesmo até de os fatos acontecerem. Por isso, entendo que incide sobre a dinâmica decisória do gabinete um fenômeno que classifico como procedimentalização. Observei que a maior parte desses projetos de sentença já estão prontos e demandam apenas preenchimento, considerando as características particulares de cada caso concreto (número do processo, nome do réu, relatório dos fatos e afins).

Percebo que a padronização das decisões tem por objetivo possibilitar a concretização do elemento punitivo inerente ao direito penal, por isso não é uma sequência desconexa, já que destinada a um objetivo fim. A produção de decisões em escala padronizada é uma técnica empregada com o objetivo de preservar a presunção de culpabilidade e viabilizar a execução antecipada do elemento aflitivo inerente à pena. Portanto, as decisões são procedimentalizadas para dar lugar a fins específicos, orientados, por sua vez, por um processo de sujeição criminal. A construção dessa dinâmica só é possível porque nela opera diretamente a concepção moral dos atores que detém o poder decisório no âmbito do caso concreto, guiado pelos jogos classificatórios.-

Nessa dinâmica de procedimentalização orientada à manutenção da presunção de culpa, todo ritual das audiências era organizado em função da juíza, de modo a possibilitar que ele aconteça só por formalidade. Nessa dinâmica, o réu e seus advogados são os que menos importam. A prioridade é sempre daqueles que compõem a família judicial. Por isso, os horários podem ser modificados em função das particularidades da própria juíza ou em função da agenda dos demais atores que compõem a família judicial. É interessante observar que a peça denominada Alegações Finais por Memoriais, apresentada tanto pela defesa quanto pela acusação após a Audiência de Instrução e Julgamento de forma escrita, não é lida na integralidade pelos assessores. No momento da produção da Sentença, a consulta da peça do Ministério Público visa diretamente à página que contém os pedidos. O objetivo é verificar em quais artigos foi 
requerida a condenação dos réus, para então reproduzi-los na sentença, confeccionada sem considerar os argumentos escritos apresentados pela defesa.

Até o momento das Audiências de Instrução e Julgamento, todos os casos são tratados como casos semelhantes, apenas o ato da audiência tem o potencial de transformar um caso semelhante em um caso excepcional. Isto porque, embora o ritual da audiência também tenha como ponto de partida a procedimentalização, o contato da juíza com as identidades de todos os atores do processo pode provocar as suas moralidades e, portanto, tem o potencial de desconstruir a identidade do sujeito criminal, inviabilizando a incriminação desse sujeito. Inclusive, a principal característica prática dos casos excepcionais é exatamente o fato de que o modelo de sentença não será a base para o ato de julgar. A sentença não será preenchida pelos assessores, mas construída pela própria juíza. Todavia, cumpre ressaltar que esse rompimento de expectativas não está relacionado com a produção de provas ou com o contato de novas narrativas, mas prescinde o contato com as identidades das partes, que podem não corresponder ao perfil projetado pelo julgador. Ressalto que dentro desse processo de produção de decisões e sentenças prevalece uma estrutura previamente estabelecida para a produção de (in)justiças que, por sua vez, é viabilizado pela procedimentalização, circunstância assimilada por julgador, acusação, bem como pela defesa, ainda que de forma mitigada a depender de maior ou menor proximidade com a família judicial.

\section{REFERÊNCIAS}

1. ADORNO, Sérgio, PASINATO, W. Violência e impunidade penal: da criminalidade detectada à criminalidade investigada. Dilemas: Revista de Estudos de Conflito e Controle Social, v. 3, n. 7, p. 51-84, jan./fev./mar. 2010. Disponível em: https://nev.prp. usp.br/wp-content/uploads/2015/04/Dilemas7Art3.pdf. Acesso em: 13 jan. 2021.

2. ALEXANDER, Michelle. A nova segregação: racismo e encarceramento em massa. São Paulo: Boitempo, 2017.

3. ALMEIDA JÚNIOR, João Mendes de. O processo criminal brasileiro. 3. ed. Rio de Janeiro: Typ. Baptista de Souza, 1920.

4. BLUMBERG, Abraham. The Practice of Law as a Confidence Game: Organizational Cooptation of a Profession. Law \& Soc'y Rev., v.15, p. 31-38, 1967.

5. BORGES, Ana Clara Davila; VINUTO, Juliana. Presunção da culpa: racismo institucional no cotidiano da justiça criminal em Niterói (RJ). Revista PerCursos, Florianópolis, v. 
21, n.45, p. 140-172, jan./abr. 2020. Disponível em: https://revistas.udesc.br/index.php/ percursos/article/view/1984724621452020140. Acesso em: 13 jan. 2021.

6. EILBAUM, Lucía. Los casos de policía en la Justicia Federal en Buenos Aires: el pez por la boca muere. 1. ed. Buenos Aires: Antropofagia, 2008. 144 p.

7. EILBAUM, Lucía. Sobre crenças, verdades e versões: processos de investigação criminal na província de Buenos Aires (Argentina). In: KANT DE LIMA, Roberto; PIRES, Lenin; EILBAUM, Lucía. (org.). Conflitos, direitos e moralidades, em perspectiva comparada. 1. ed. Rio de Janeiro: Garamond, 2010. p. 171-186.

8. EILBAUM, Lucía. Só por formalidade: A interação entre os saberes antropológico, jurídico e judicial em um Juicio Penal. Horizontes Antropológicos, v.18, n.38, p.313339, 2012. Disponível em: https://www.scielo.br/pdf/ha/v18n38/13.pdf. Acesso em: 12 jan. 2021.

9. FERREIRA, Marco Aurélio. A presunção da inocência e a construção da verdade: contrastes e confrontos em perspectiva comparada (Brasil e Canadá). Rio de Janeiro, 2013.

10. FIGUEIRA, Luiz Eduardo. O Ritual Judiciário do Tribunal do Júri: o caso do ônibus 174. Porto Alegre: Sérgio Antonio Fabris Editor, 2008.

11. FOUCAULT, Michel. A verdade e as formas jurídicas. Rio de Janeiro: PUC, 1999.

12. GARAU, Marilha Gabriela Reverendo. Resquícios do Sistema Inquisitorial: análise da aplicação da Súmula 70 do TJ/RJ nas Sentenças Relacionadas à Lei 11.343/06. In: Direito Penal, Processo Penal e Constituição. CONPEDI, 2015.

13. GARAU, Marilha Gabriela Reverendo. Silêncio no Tribunal: um estudo contrastivo das representações judiciais sobre crimes de tráfico de drogas no Rio de Janeiro e em Málaga na Espanha. 2020. Tese (Doutorado em Ciências Jurídicas e Sociais) - Programa de Pós-Graduação em Sociologia e Direito, Universidade Federal Fluminense, Niterói, 2020.

14. GEERTZ, Clifford. O saber local: fatos e leis em uma perspectiva comparativa. Petrópolis: Vozes, 1998.

15. GERALDO, Pedro Heitor Barros; ALMEIDA, Fábio Ferraz de. A produção da decisão judicial: uma abordagem praxeológica dos julgamentos judiciais. Revista de Estudos Empíricos em Direito, v. 4, p. 23-37, 2017. Disponível em: https://reedrevista.org/ $\mathrm{reed} / \mathrm{article} / \mathrm{view} / 271$. Acesso em: 12 jan. 2021.

16. GERALDO, Pedro Heitor Barros; RAMOS, Juliana Sanches. Em razão da sua raça: o racismo ordinário no raciocínio jurídico dos operadores do Direito. 2020. Disponível em: www.jota.info/opiniao-e-analise/colunas/judiciario-e-sociedade/em-razao-da-suaraca-21082020. Acesso em: 25 ago. 2020.

17. GOFFMAN, Erving. Ritual de interação: ensaios sobre o comportamento face a face. 
Tradução Fábio Rodrigues Ribeiro da Silva. Petrópolis: Vozes, 2011. 255 p.

18. JESUS, Maria Gorete Marques. O que está no mundo não está nos autos: a construção da verdade jurídica nos processos criminais de tráfico de drogas. 2016. 275 f. Tese (Doutorado em Sociologia) - Departamento de Sociologia, Universidade de São Paulo, São Paulo, 2016.

19. KANT DE LIMA, Roberto. Polícia e exclusão na cultura judiciária. Revista de Sociologia da USP, São Paulo, v. 9, n. 1, p. 169-183, maio 1997. Disponível em: https:// www.revistas.usp.br/ts/article/view/86542. Acesso em: 25 ago. 2020.

20. KANT DE LIMA, Roberto. Polícia, Justiça e Sociedade no Brasil: uma abordagem comparativa dos modelos de administração de conflitos no espaço público. Revista de Sociologia e Política, Curitiba, n. 13, p. 23-38, nov. 1999. Disponível em: https://www. revistas.usp.br/ts/article/view/86542. Acesso em: 25 ago. 2020.

21. KANT DE LIMA, Roberto. Sensibilidades jurídicas, saber e poder: bases culturais de alguns aspectos do Direito brasileiro em uma perspectiva comparada. Anuário Antropológico, v. 2, p. 25-51, 2010. Disponível em: https://journals.openedition.org/ aa/885. Acesso em: 12 jan. 2020.

22. MENDES, Regina Lúcia Teixeira. Do princípio do livre convencimento motivado: legislação, doutrina e interpretação dos juízes brasileiros. Rio de Janeiro: Editora Lumen Juris, 2011.

23. MEDEIROS, Flávia. Linhas de investigação: uma etnografia das técnicas e moralidades numa Divisão de Homicídios da Polícia Civil do Rio de Janeiro. Rio de Janeiro: Autografia, 2018.

24. MIRANDA, Ana Paula Mendes de. Cartório: onde a tradição tem registro público. Antropolítica: Revista. Contemporânea de Antropologia e Política, v. 8, n. 1, p. 5975,2000 .

25. MISSE, Michel. A construção social do crime no Brasil. In: MISSE, Michel. (org.). Acusados e acusadores: estudos sobre ofensas, acusações e incriminações. Rio de Janeiro: Revan/Faperj, 2008.

26. MISSE, Michel. (org.). O inquérito policial no Brasil: uma pesquisa empírica. Rio de Janeiro: Editora Booklink/Fenapef/Necvu, 2010.

27. MONTEIRO, Fabiano Dias. Retratos em preto e branco, retratos sem nenhuma cor: a experiência do disque-racismo da Secretaria de Segurança Pública do Estado do Rio de Janeiro. 2003. Dissertação (Mestrado) - Programa de Pós Graduação em Sociologia e Antropologia, Universidade Federal do Rio de Janeiro, 2003.

28. NUÑEZ, Izabel Saenger. "Aqui não é a casa de vingança, é a casa da justiça!": Moralidades, hierarquizações e desigualdades na administração de conflitos no Tribunal do Júri. 2018. Tese (Doutorado em Antropologia) - Programa de Pós-Graduação em Antropologia, Universidade Federal Fluminense, Niterói, 2018. 
29. PAES, Vivian Ferreira. Do inquérito ao processo: análise comparativa entre polícia e Ministério Público no Brasil e na França. Revista de Estudos de Conflito e Controle Social, v. 3, n. 7, p. 109-141, 2010. Disponível em: https://revistas.ufrj.br/index.php/ dilemas/article/view/7202. Acesso em: 14 jan. 2021.

30. RENOLDI, Brigida. Narcotrafico y justicia en Argentina: la autoridad de lo escrito en el juicio oral. Buenos Aires: Antropofagia, 2008.

31. SARRABAYROUSE, Maria José. Poder Judicial Transición del escriturismo a la oralidad. 1998. Tesis de Licenciatura. Facultad de Filosofía y Letras Universidad de Buenos Aires. 1998.

32. SINHORETTO, Jacqueline; GIANE Silvestre. Desigualdade racial e segurança pública em São Paulo: letalidade policial e prisões em flagrante. Sumário executivo. São Paulo: Universidade Federal de São Carlos; Grupo de Estudos sobre Violência e Administração de Conflitos, 2014.

33. SAPORI, Luís Flávio. A administração da Justiça Criminal numa área metropolitana. Revista Brasileira de Ciências Sociais, n. 29, p. 143-156, out. 1995. Disponível em: http://anpocs.com/images/stories/RBCS/rbcs29_08.pdf. Acesso em: 12 jan. 2021.

34. VIDAL, Paula Chagas Lessa. 2013. "Os donos do carimbo": investigação policial como procedimento escrito. Rio de Janeiro: Lumen Juris, 2013.

35. WEBER, Max. Economia e sociedade: fundamentos da sociologia compreensiva. Brasília: UnB, 1999.

Marilha Gabriela Reverendo Garau

Doutora em Ciências Jurídicas e Sociais pelo Programa de Pós-graduação em Sociologia e Direito da Universidade Federal Fluminense. Mestre em Direito Constitucional pelo Programa de Pós-graduação em Direito Constitucional pela Universidade Federal Fluminense. Mestre em Direito Penal e Política Criminal pela Universidade de Málaga na Espanha. ID ORCID: https:// orcid.org/0000-0002-7421-4226. E-mail: marilhagarau@gmail.com. 